\title{
ISSN 0004-9727
}

\section{BULLETIN Volume 21 (1980)}

of the Australian Mathematical Society

"Please note a variation in the intended rate of production of the Bulletin. ONLY ONE volume (volume 20) will be published in 1979, although subscribers paid for two volumes (volumes 20 and 21). This change will be rectified in 1980 when volumes 21 and 22 will appear AND subscribers will be charged for VOLUME 22 ONLY in respect of that year.

We much regret any inconvenience caused to our customers by the above re-scheduling, and would like to emphasize that these changes have been made necessary by causes beyond our control".

N. C. Weber

P. R. Scott

K. Narsimha Reddy

Jonathan A. Hillman

P. D. Tuan and V. V. Anh

Hazar Abu-Khuzam and Adil Yaqub

F. E. Bennett and N. S. On the spectrum of Stein quasigroups Mendelsohn

S. Nababan and K. L. Teo

E. N. Dancer

Ivan Singer

Gary D. Richardson

R. K. Singh and S. D. Sharma

David E. Dobbs

V. N. Joshi application to nonlinear eigenvalues support in normed linear spaces

Applications of convergence spaces

Non-compact composition operators

On flat finitely generated ideals

A determinant for rectangular matrices
Rates of convergence for $U$-statistics with varying kernels

Further inequalities for convex sets with lattice point constraints in the plane

Integral inequalities and applications

Trivializing ribbon links by Kirby moves

Radii of convexity of two classes of regular functions

A commutativity theorem for division rings Number 1

\section{Abstracts of Australasian PhD theses}

Russell Rimmer

M. Rimmer

Michael Kelly Mara

Daniel G. Kildea

Allison Heard

Howard Paul Edwards

Nicholas C. Wormald
Existence and uniqueness of weak solutions of the Cauchy problem for parabolic delay-differential equations

An implicit function theorem with symmetries and its

Extensions with larger norm and separation with double

Generic bifurcation from symmetric fixed points of involutory area preserving maps

Skew polynomial rings and skew power series rings . $\quad 149$

Empirical Bayes with a changing prior

Median estimators for regression models-the BrownMood approach

The solution of the order conditions for general linear methods

Bayes sequential design procedures: theory and applications 157

Some problems in the enumeration of labelled graphs 


\title{
BULLETIN OF THE AUSTRALIAN MATHEMATICAL SOCIETY
}

\author{
Editor: \\ Sidney A. Morris \\ Deputy Editor: \\ K. R. Pearson \\ Honorary Editor: \\ B. H. Neumann
}

\section{Associate Editors}

\author{
Robert S. Anderssen \\ Alan L. Andrew \\ B. D. Craven \\ Brian A. Davey \\ G. E. Davis \\ J. R. J. Groves
}
D. A. Holton
D. C. Hunt
J. S. Maritz
Rodney Nillsen
A. J. van der Poorten
Ian Robinson
J. H. Rubinstein

Leon Simon

G. Szekeres

D. G. Tacon

Colin J. Thompson

H. B. Thompson

R. F, C. Walters

\section{Assistant Editors}

Robert S. Anderssen

M. S. Brooks

\section{INFORMATION FOR AUTHORS}

The BULLETIN of the Australian Mathematical Society aims at quick publication of original research in all branches of mathematics. Timely expository articles are also welcomed.

To ensure speedy publication, editorial decisions on acceptance or otherwise are taken quickly, normally within a month of receipt of the paper. Papers are accepted only after being evaluated by the Editor and an Associate Editor or another expert. Of course responsibility for the correctness of results published in the BULLETIN remains with the authors.

For a paper to be acceptable for publication, not only should it contain new and interesting results but also

(i) the exposition should be clear and attractive, and

(ii) the manuscript should be in publishable form, without revision.

Nevertheless some meritorious papers will have to be rejected because speed of publication involves space limitations.

Authors should submit THREE clean, high quality copies to

The Editor,

Bulletin of the Australian Mathematical Society.

Department of Pure Mathematics,

La Trobe University.

Bundoora, Victoria 3083, Australia

and should retain the original typescript of their papers, as material submitted to the BULLETIN will usually not be returned. Authors should note that each paper must include an abstract of not more than 200 words.

Details of editorial policy are given on the inside back cover.

\section{Abstracts of PhD Theses}

The BULLETIN endeavours to publish abstracts of all accepted Australasian PhD theses in mathematics. One restriction, however, is that the abstract must be received by the Editor within 3 months of the degree being approved.

\section{(c) Copyright by Australian Mathematical Society 1980.}

Copyright. Apart from any fair dealing for scholarly purposes as permitted under the Copyright Act, no part of this BULLETIN may be reproduced by any process without written permission from the Treasurer of the Australian Mathematical Society. 